Disponível em

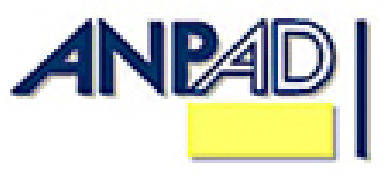

http://www.anpad.org.br/rac

RAC, Rio de Janeiro, v. 18, Edição Especial, art. 1, pp. 1-21, Dezembro 2014

http://dx.doi.org/10.1590/1982-7849rac20141177

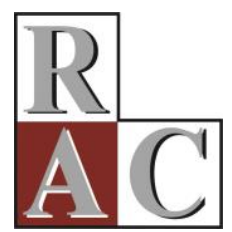

$(c)$ EY-NO

\title{
O Que Gestão Estratégica Tem a Ver com Capitalismo(s)?
}

\section{What Does Strategic Management Have to do With Capitalism(s)?}

Alexandre de Almeida Faria

E-mail: alex.faria@fgv.br

Fundação Getulio Vargas - EBAPE/FGV

Praia de Botafogo, 190, Sala 524, Botafogo, 22250-900, Rio de Janeiro, RJ, Brasil.

Takeyoshi Imasato

E-mail: tkimasato@gmail.com

Universidade Federal do Rio Grande do Sul - EA/UFRGS

Rua Washington Luiz, 855, Sala 307, Centro, 90010-460, Porto Alegre, RS, Brasil.

Ana Lucia Malheiros Guedes

E-mail: almguedes@gmail.com

Universidade do Grande Rio - PPGA/UNIGRANRIO

Rua da Lapa, 86, 20021-180, Rio de Janeiro, RJ, Brasil.

Artigo recebido em 14.11.2012. Última versão recebida em 18.07.2014. Aprovado em 31.07.2014. 


\title{
Resumo
}

Os debates acerca do capitalismo no contexto de sucessivas crises da globalização neoliberal, apesar de negligenciados pela literatura de gestão estratégica (GE), são de central importância para estrategistas e acadêmicos de economias emergentes. Informados pela hegemonia do capitalismo histórico ocidental e, em resposta à vinculação da literatura de GE dos EUA aos discursos do capitalismo neoliberal como opção única, a literatura europeia abraçou a teoria de variedades de capitalismo e construiu a abordagem de estratégia como prática social. Por meio de um diálogo com a área de estudos internacionais, este artigo discute que a hegemonia euro-americana contemporânea em GE ajuda a construir a autoridade legítima de estrategistas das grandes corporações, tanto a invisibilizar estrategistas euro-americanos de Estado quanto a deslegitimar estrategistas e organizações do resto do mundo que representam outros tipos de capitalismo ou alternativas ao ocidentalismo histórico. Ao final, os autores argumentam que o campo de estratégia no Brasil deve fomentar uma perspectiva de geopolítica do conhecimento em estratégia que ajude a superar algumas das restrições impostas pelo capitalismo histórico ocidentalista e a permitir a difusão de outros tipos de capitalismo e alternativas não ocidentalistas.

Palavras-chave: estratégia; economias emergentes; capitalismo; gestão estratégica; legitimidade.

\begin{abstract}
The many debates about capitalism within the context of the successive crises of neoliberal globalization, although overlooked by the field of strategic management (SM), are of central importance to strategists and academics from emerging economies. In response to the way SM in the US has been linked to discourses portraying neoliberal capitalism as the only option, European literature has embraced the perspective of varieties of capitalism and developed the strategy as practice approach. Through a dialogue with international studies, this article argues that the Euro-American contemporary hegemony in GE helps build the legitimate authority of strategists from large corporations and keep Euro-American state strategists invisible and delegitimizes strategists and organizations from the rest of the world that represent other types of capitalism or alternatives to the Occidentalist order. In the end, the authors posit that the strategy field in Brazil might foster a geopolitical perspective on GE that could overcome some of the restraints imposed by historic capitalism and enable the diffusion and legitimation of other types of capitalism and non-Occidentalist alternatives.
\end{abstract}

Key words: strategy; emerging economies; capitalism; strategic management; legitimacy. 


\section{Introdução}

O capitalismo neoliberal tem como alicerces institucionais o direito de propriedade, o livre mercado e a participação do Estado na criação e na preservação de instituições e práticas correspondentes (Harvey, 2007). Desde o início da década de 1970, a proliferação de reformas e estratégias vinculadas ao discurso de que não há alternativa ao capitalismo neoliberal, as seguidas crises que reforçaram as desigualdades entre privilegiados e desprivilegiados (Chase-Dunn, 2010; Harvey, 2014; Piketty, 2014) e as assimetrias entre o Ocidente e o resto do mundo (Brenner, 1999; Harvey, 2007; Shefner \& Férnandez-Kelly, 2011) tornaram-se desafios estratégicos para sociedades e comunidades em escala global, mas não para a pesquisa em gestão estratégica (Vaara \& Durand, 2012).

Ao alcançarem um nível sem precedentes de poder (geo)político, grandes corporações das economias desenvolvidas protagonizaram um novo desenho de alianças entre os poderes do Estado e do capital, que caracterizam não uma disfunção do capitalismo neoliberal, mas sim o aprofundamento de contradições estabelecidas pelo capitalismo histórico ocidentalista ${ }^{(1)}$ (Arrighi, 2012; Wallerstein, 2011). Essas grandes corporações passaram a exercer um papel central na expansão do capitalismo ocidentalista por meio de crescente monopolização e financeirização (Harvey, 2014; Madeley, 2008). Esse quadro privilegia elites e se opõe a outros tipos de capitalismos do resto do mundo e a alternativas à ordem ocidentalista (B. Santos, 2009; Martins, 2011).

Grandes corporações tiveram suas estratégias e operações questionadas em escala global no início dos anos 2000, particularmente devido a fraudes administrativas. As críticas produzidas pela área de gestão estratégica (GE), entretanto, restringiram-se a afirmar que teorias e escolas de negócios tinham que mudar para que as virtudes do capitalismo corporativo pudessem prevalecer em escala global (ver Ghoshal, 2005; Whittington et al., 2003). Esses argumentos desprezaram duas questões relevantes: primeiro, a Crise Asiática, no final dos anos 1990, foi acompanhada por estratégias para evitar a deslegitimação do capitalismo neoliberal e da ordem ocidentalista subjacente (Stiglitz, 2002); segundo, os eventos de 11/9 e a ascensão do unilateralismo dos EUA foram acompanhados pela emergência do chamado novo imperialismo ${ }^{(2)}$ como meio de garantir a hegemonia ocidentalista mundialmente (Harvey, 2003). Em nome da retomada da confiança nas grandes corporações, a gestão da legitimidade dessas organizações no resto do mundo se tornou prioridade para estrategistas, instituições e acadêmicos nos EUA e na Europa (Kostova \& Roth, 2002; Porter \& Kramer, 2011). Esse quadro foi acompanhado por uma intensa internacionalização da área de GE dos EUA ao redor do mundo, principalmente em economias emergentes.

Sob uma perspectiva histórico-geopolítica que torna visível e desafia a matriz eurocêntrica ${ }^{(3)}$ que estabeleceu a hierarquia entre Ocidente e o resto do mundo por meio da codificação racial das diferenças e da constituição de uma estrutura assimétrica de controle de trabalho e seus produtos e recursos (Quijano \& Wallerstein, 1992), argumenta-se aqui que a hegemonia euro-americana em GE tem sido um recurso importante para manter o poder do capitalismo histórico ocidentalista, em detrimento de alternativas. Assim como o campo das ciências sociais tem exercido papel central para a construção e a legitimação do Estado moderno e do capitalismo ocidental como ordem hegemônica ou monopolista (Wallerstein, 2011), a área de GE também tem importância geopolítica para a legitimação do capitalismo neoliberal como ordem hegemônica.

A área de GE, devido às amarras ocidentalistas que ficaram virtualmente invisíveis para seus defensores (mas também para pesquisadores), enfrenta dificuldades para lidar com esse grande cenário. Logo após a crise financeira global de 2007-2008, um dos proeminentes acadêmicos de GE afirmou, nas páginas da McKinsey Quarterly, que crises são normais e que é momento de abraçarmos mais uma oportunidade para tão e somente "repensarmos nosso modo de gestão" (Rumelt, 2008, p. 2). Na Europa, há aqueles que defendem o fortalecimento das instituições que sustentam o domínio do capitalismo histórico e bloqueiam a construção de uma área multipolar de GE (Witcher \& Chau, 2012). Tendo em vista a cumplicidade da área na produção e na propagação da crise da ordem neoliberal (Clegg, Carter, Kornberger, \& Schweitzer, 2011; Whittington et al., 2003), esse quadro também resultou em resistências 
em diferentes países e regiões - especialmente em economias emergentes (e.g., Alcadipani \& Bertero, 2012) - que não foram suficientemente desenvolvidas em GE.

Na Europa, influenciados pela teoria de variedade de capitalismos e pelo conceito de sistemas nacionais de negócios, construídos para contrabalançar o consenso imposto pelos EUA, alguns autores passaram a criticar o domínio dos estadunidenses em GE nos anos 1990 (ver Pettigrew, Thomas, \& Whittington, 2002). Essas críticas informaram a criação da perspectiva de estratégia como prática social como uma alternativa, a qual não foi capaz de cumprir as promessas correspondentes por não problematizar questões mais estruturais (Vaara \& Whittington, 2012). Apesar de defender uma perspectiva ampla, vinculada às ciências sociais e em oposição à dominação do positivismo e da economia em GE, essa perspectiva não problematizou sua vinculação ao capitalismo histórico e acabou contribuindo para agudizar problemas protagonizados por $\mathrm{GE}^{(4)}$.

Por meio de uma abordagem crítica que traz à tona questões de geopolítica contempladas pela literatura de estudos internacionais ${ }^{(5)}$, este trabalho argumenta que economias emergentes devem assumir responsabilidades para fomentar a coconstrução de uma área não ocidentalista de GE. Para tanto, este artigo está dividido em mais quatro seções. Na próxima, os autores mostram que o conhecimento da área de GE está vinculado aos discursos do capitalismo neoliberal como única opção e, consequentemente, ao capitalismo histórico ocidentalista. Na terceira seção, será analisado como a teoria europeia de variedades do capitalismo e a criação da perspectiva de estratégia como prática social ajudaram a reforçar problemas protagonizados por GE. Na quarta seção, mostrar-se-á como e por que a área de estratégia no Brasil tem tanto reproduzido quanto desafiado esse quadro hegemônico. Por fim, são retomadas as principais contribuições deste artigo na última seção.

\section{Legitimidade e Autoridade em Gestão Estratégica}

Criada e comandada pelos EUA, a área de GE tem fomentado a legitimação de um tipo específico de estrategista - i.e., o estrategista da grande corporação (conhecido também como CEO) - em detrimento de outros tipos de estrategista e organização. Tendo como base o trabalho de um dos pais da disciplina (Chandler, 1977), a área se baseia no argumento de que o capitalismo gerencial - governado por corporações modernas, que são administradas, por sua vez, por gerentes assalariados que se organizam por meio de um sistema hierárquico baseado em mérito - é superior a outros tipos de capitalismo.

O conhecimento de GE continua sendo fomentado e governado não somente por acadêmicos, mas também por grandes empresas de consultoria, think tanks, escolas de negócios, organizações acadêmicas e outras instituições do mundo euro-americano (Bowman, Singh, \& Thomas, 2002), sob uma perspectiva que, tal é a manifestação de assimetria, foi classificada como imperial por acadêmicos europeus da área de estudos organizacionais (Clegg et al., 2011). Enquanto outros autores europeus afirmam que a desconexão da pesquisa em estratégia com questões realmente importantes, em termos globais, pode-se indicar uma cumplicidade da área com as seguidas crises contemporâneas, autores de outras áreas, em especial a de estudos internacionais, apontam que a crise do capitalismo neoliberal deflagrada em 20072008 é a parte mais óbvia da transição da dominação do ocidentalismo e do conhecimento ocidentalista. Esta literatura aponta que, ao invés de um futuro marcado pelo acirramento da dominação imperial dos EUA ou até mesmo por um colapso global de grandes proporções (como a ascensão de um fascismo global, por exemplo), o Ocidente deveria ajudar a construir condições para que economias emergentes assumam novas responsabilidades estratégicas (e.g., B. Santos, 2009; Hurrell \& Sengupta, 2012; Shefner \& Fernández-Kelly, 2011; Sklair, 2011).

A bagagem ocidentalista que informa a área de GE tornou-se mais extremada não somente por causa dos discursos e reformas que assumiram o capitalismo neoliberal como opção única em escala global a partir dos anos 1970 (acompanhada pela síndrome do TINA - acrônimo para there is no alternative, inaugurada por Margareth Thatcher ao afirmar categoricamente que não havia alternativa 
ao neoliberalismo), mas também pelas seguidas crises dessa suposta nova ordem mundial. Esse quadro tornou-se mais problemático a partir do momento em que estrategistas de Estado do mundo euroamericano passaram a exercer um papel central para viabilizar a hegemonia ${ }^{(6)}$ do capitalismo ocidentalista (imposta ao próprio Ocidente e ao resto do mundo ao longo de mais de quinhentos anos [Wallerstein, 2011]); logo após os eventos de 11/9, em 2001; e a correspondente militarização da ordem neoliberal e ascensão do unilateralismo dos EUA (Steger, 2009).

Em termos geopolíticos, a área vem enfrentando um novo desafio hegemônico por causa da ascensão das economias emergentes e das seguidas crises do capitalismo neoliberal e do ocidentalismo subjacente, que passaram a ser importantes não apenas para as economias emergentes, mas também para o Ocidente. Enquanto o capitalismo da China vem sendo descrito pela literatura de estudos internacionais como possivelmente o novo capitalismo dominante (Arrighi, 2007), defensores da ordem neoliberal ocidentalista descrevem o mesmo como ameaçador para a ordem global, sob uma perspectiva que reforça a hierarquia entre o Ocidente e o resto do mundo (ver Bremmer, 2010; Meltzer, 2012). A literatura euro-americana de GE descreve as economias emergentes não como um novo centro legítimo de poder, mas sim como um problema global. Mais especificamente, autores sugerem que as deficiências institucionais e epistêmicas desses países têm que ser corrigidas para evitar que seus problemas locais se transformem em problemas globais (Peng \& Parente, 2012). Por isso, a institucionalização da grande corporação em escala global tornou-se questão prioritária.

Até o advento do capitalismo neoliberal como única opção, a grande corporação era tida como instituição estadunidense e vinculada ao americanismo pós-Segunda Guerra; por isso a grande corporação era tanto copiada quanto criticada na Europa e no resto do mundo. Especialmente na Europa, a diversidade de organizações e estrategistas era tolerada, e a área de GE não era tão importante quanto nos EUA. A ascensão do capitalismo neoliberal promoveu, devido ao protagonismo de grandes corporações, o interesse de pesquisadores europeus nestas corporações como a única opção no início dos anos 1990, assim como as críticas à área de GE, informadas pela teoria de variedades do capitalismo e pela literatura de sistemas nacionais de negócios, que levariam posteriormente à criação da perspectiva de estratégia como prática social (Whittington, 1993). Os escândalos corporativos no início dos anos 2000 foram particularmente importantes para a ascensão da perspectiva europeia de estratégia como prática social e a consequente formação da hegemonia euro-americana, comandada pelos EUA, na área de GE.

Com a Crise Asiática, no final dos anos 1990, que levou ao ocaso do Consenso de Washington ${ }^{(7)}$, e com a ascensão do unilateralismo dos EUA após os eventos de 11/09, a corporação moderna foi subitamente representada como "a instituição essencial do capitalismo global" (Lipartito \& Sicilia, 2004, p. 1). Autores europeus vinculados à perspectiva de estratégia como prática social, com base na teoria de variedades de capitalismo e na literatura de sistemas nacionais de negócios, passaram, então, a descrever grandes corporações como uma instituição também europeia (e.g., Whitley, 1999; Whittington \& Mayer, 2005). Em seguida, grandes corporações passaram a ser descritas pela literatura euro-americana como organizações que devem transcender a divisão entre Ocidente e resto do mundo.

O banco de investimentos Goldman Sachs - notório não apenas por protagonizar a crise financeira global de 2007-2008, mas também por promover o tráfico de informações e de poderes entre a Casa Branca e Wall Street (Jacobs \& King, 2010) - publicou, no início da década anterior, a previsão de que a soma dos PIBs das economias emergentes (Brasil, Rússia, Índia e China - os BRIC) seria maior do que a metade do PIB dos países do G6 (França, Alemanha, Itália, Japão, EUA e Reino Unido) em 2025 - superando o total do G6 a partir de 2040 (Wilson \& Purushothaman, 2003). Tal previsão serviu para reforçar o argumento de que o capitalismo global governado por corporações globais (i.e., corporações à imagem e semelhança das corporações euro-americanas) levaria ao multipolarismo, a despeito da crescente militarização e financeirização do capitalismo neoliberal liderado pelos EUA (Arrighi, 2007; Harvey, 2014). Enquanto estrategistas de Estado do mundo euro-americano ficaram ainda mais importantes para a manutenção da hegemonia do capitalismo neoliberal ocidentalista, a ascensão dos países dos BRICs foi vinculada e condicionada ao desempenho estratégico das grandes corporações das economias emergentes por acadêmicos e empresas de consultoria da área de GE (e.g., Accenture, 2008). Além de ajudar a invisibilizar estrategistas euro-americanos de Estado e a deslegitimar estrategistas de 
Estado das economias emergentes, esse processo de institucionalização ajudou a bloquear outros tipos de organização e de estrategista que representassem outros tipos de capitalismo (i.e., não-ocidentalista) ou alternativas ao capitalismo histórico.

O argumento euro-americano de que a grande corporação tornou-se uma instituição universal do capitalismo global consolidou um longo processo de construção da autoridade legítima do capitalismo ocidentalista e dos conquistadores (sobre os conquistados), iniciado há mais de quinhentos anos. Esse argumento ajudou a manter invisível o quadro de disputa - que, no fundo, representa uma coalizão duopolista - envolvendo tipos de capitalismo comandados pelos EUA e Europa, e o lado mais sombrio das assimetrias, envolvendo o Ocidente e o resto do mundo (Arrighi, 2012; Mignolo, 2011) - com especial destaque para países que foram classificados por instituições neoliberais estadunidenses como economias emergentes. A literatura de GE, ajudando a restringir a construção de conhecimento acadêmico enunciado em economias emergentes, passou a se preocupar tanto com reputação, transparência, responsabilidade social, combate à pobreza, desenvolvimento econômico, e reformas institucionais incrementais no resto do mundo, quanto com lucros e desempenho competitivoeconômico das grandes corporações (Brugmann \& Prahalad, 2007; Mahajan \& Banga, 2006).

Os debates produzidos pela literatura de estudos internacionais acerca da globalização, do neoliberalismo e do capitalismo global (e.g., B. Santos, 2006; Sklair, 2011) continuaram sendo ignorados pela literatura de GE. Por causa da ascensão de corporações de economias emergentes e dos países que compõem os BRICs e especialmente após a deflagração da crise da financeirização do capitalismo em 2007-2008, esse quadro de disciplinação ocidentalista tornou-se um problema estratégico global (Shefner \& Fernández-Kelly, 2011). Em outras palavras, a dominação euro-americana na área de GE tornou-se um problema não somente para estrategistas e acadêmicos da área, mas também para uma crescente população de desprivilegiados (ilustrado, por exemplo, pelos movimentos occupy e antiausteridade).

Por sua vez, a McKinsey e outras instituições dos EUA que vêm financiando e governando a área de GE desde o início da década de 1970 passaram a descrever o quadro contemporâneo como ameaçador para as corporações e seus estrategistas. Aproveitando os privilégios atribuídos pela ordem neoliberal à segurança global a partir da inauguração da guerra ao terror, essa literatura reforçou os discursos que defendem o controle de novos territórios para a expansão da globalização neoliberal. Por exemplo, ao defender que CEOs devem assumir responsabilidades de ordem sócio(geo)política, a literatura argumenta que os ataques de ativistas ${ }^{(8)}$ às corporações e a outras instâncias da sociedade estão cada vez mais intensos devido às deficiências institucionais de diferentes países do resto do mundo. Autores influentes afirmaram (e.g., Porter \& Kramer, 2011) que os ativistas em economias emergentes podem tanto destruir a reputação das empresas como comprometer a evolução do capitalismo global ocidental. A McKinsey afirma categoricamente que CEOs têm a obrigação de transformar esse quadro de forças políticas e sociais adversas em oportunidades de mercado e, assim, assumir a liderança na resolução de problemas sociais em economias emergentes que, no fundo, são globais, sendo estes problemas como mudanças climáticas, assistência de saúde e pobreza (ver Davis, 2006).

A literatura argumenta que a expansão do ativismo no resto do mundo pode desestabilizar as bases de legitimidade que sustentam a autoridade dos estrategistas das grandes corporações (Baron, 2010; Porter \& Kramer, 2006, 2011). Por meio de atribuição de atraso e ameaças ao resto do mundo, essa literatura reforça a invisibilização dos estrategistas de Estado que protagonizam a expansão do capitalismo histórico ocidentalista e a deslegitimação da autoridade de estrategistas do governo do resto do mundo. A literatura de estudos internacionais ressalta que a literatura euro-americana continua atribuindo problemas ao outro eternamente atrasado para legitimar a autoridade do ocidentalismo e de intervenções correspondentes (Arrighi, 2012; Hurrell \& Sengupta, 2012). Autores de ciência política nos EUA ressaltam que as seguidas crises do capitalismo financeiro mostraram que as mais visíveis e conhecidas formas de corrupção - tais como subornos - não ocorrem somente em Washington "porque a indústria literalmente impregnou o núcleo do governo" (Jacobs \& King, 2010, p. 797).

Práticas classificadas como ativismo pela literatura de GE dizem respeito também a práticas de outros tipos de estrategista, organização e instituição, que vêm desafiando, com diferentes níveis de 
sucesso, a ordem neoliberal, e fomentando outros tipos de capitalismo e alternativas não ocidentalistas (Mignolo, 2011; Shefner \& Fernández-Kelly, 2011). Como ressaltado pela teoria pós-colonial, não é incomum classificar como ativistas, primitivos, ou bárbaros todos aqueles que colocam em xeque a autoridade do ocidentalismo (Young, 2003). Segundo a literatura de Relações Internacionais (RI), especialmente após a ascensão do unilateralismo dos EUA e o início da guerra ao Iraque e ao terror em escala global, tornou-se prioritária a imposição da autoridade legítima de estrategistas e instituições tidas como não estatais para manter invisível ou mais tolerável o uso da força (Hurrell, 2005). Esse quadro invisível de institucionalização de um regime de dominação ocidentalista que pareça hegemonia benigna, liderada pelos EUA, ajuda a explicar a crescente preocupação da literatura de gestão dos EUA e da Europa com legitimidade em décadas recentes (e.g., Suchman, 1995). Por sua vez, esse quadro ajuda a explicar por que economias emergentes devem empreender a teorização de GE sob uma perspectiva que permita a construção de uma área não ocidentalista.

Esse grande quadro informa o crescente interesse da literatura de GE em fomentar a transformação de questões sociais, culturais, e institucionais no resto do mundo - e em particular em economias emergentes - em 'oportunidades' estratégicas para grandes corporações (Baron, 2010; Porter \& Kramer, 2006), e, em paralelo, criar e comandar conhecimentos de GE focados nas especificidades institucionais de economias emergentes que, em última instância, obstruem a evolução do capitalismo global (Khanna \& Palepu, 2006; Khanna, Palepu, \& Sinha, 2005). Instituições acadêmicas, grandes empresas de consultoria e instituições transnacionais (tais como Fórum Econômico Mundial, Nações Unidas e Banco Mundial) têm compartilhado esses objetivos estratégicos com base não apenas no reconhecimento da importância econômica desses mercados para as corporações ocidentais, mas também nos temores de que economias emergentes, seus estrategistas e suas principais instituições, transformem-se em ameaça para o capitalismo ocidental liderado pelos EUA.

O que está sendo argumentado aqui é que a institucionalização de discursos e ideias por meio de disciplinas acadêmicas continua sendo um dos principais recursos para a construção de autoridade legítima do capitalismo histórico ocidentalista - i.e., dominação que pareça hegemonia, ou coerção que pareça consentimento (Mignolo, 2011; Pieterse \& Peters, 2012; Roper, 2005). Durante a Guerra Fria, frente às ameaças do comunismo e da corrida armamentista, o conhecimento acadêmico de gestão serviu para a construção da autoridade legítima no Terceiro Mundo não somente do estrategista da grande corporação, mas também do capitalismo ocidental liderado pelos EUA (Alcadipani \& Bertero, 2012). Esse processo de institucionalização da gestão sob uma perspectiva aparentemente apolítica ou científica tornava mais tolerável, ou invisível, o uso da força e da coerção frente ao risco de uma guerra nuclear no contexto do bipolarismo (Parmar, 2012). Especialmente devido à importância das grandes corporações para a hegemonia do capitalismo ocidental e para a difusão de temores referentes às deficiências institucionais e epistêmicas das economias emergentes (Bremmer, 2010; Davis, 2006), a importância (geo)política do conhecimento acadêmico de gestão continua elevada no pós-Guerra Fria (Clegg, Ibarra-Colado, \& Bueno-Rodriguez, 1999; Rodrigues, Duarte, \& Carrieri, 2012).

Esse quadro informa os autores que na Europa defendem pesquisa que torne visível o lado político das estratégias das grandes corporações (Matten, 2009) e criticam o ofuscamento de conceitos relacionados a poder e a política pelas literaturas de GE e de estratégia como prática social (Carter, Clegg, \& Kornberger, 2008; Vaara \& Durand, 2012). Em outras palavras, a gestão estratégica do conhecimento acadêmico continua sendo de central importância para manter invisível ou tolerável poderes que são exercidos sobre diferentes grupos de interesse, incluindo a própria academia.

Autores críticos em estudos organizacionais (EOs) vêm apontando, há algum tempo, que conhecimento acadêmico em gestão não é isento ou livre dos valores ou interesses ocidentalistas (Murphy \& Zhu, 2012; Prasad, 2003). Curiosamente, autores de EOs enfrentam dificuldades institucionais para analisar a área de GE. É importante lembrar que a área de strategic management foi criada na Guerra Fria em um contexto sócio-político e epistêmico no qual a academia de management, as grandes corporações e a posição dos EUA como potência hegemônica tinham sua legitimidade questionada não apenas no resto do mundo, mas também nos EUA (ver Boyle, 2004). A literatura impôs não só uma ordem epistêmica ao privilegiar um tipo de estrategista, mas também uma ordem disciplinar nas instituições de gestão ao promover uma divisão hierárquica entre GE e EOs. Enquanto a literatura 
de EOs preza a diversidade e reconhece questões de geopolítica do conhecimento - até mesmo por autores do resto do mundo (e.g., Ibarra-Colado, 2006), a literatura euro-americana de GE mantém curioso silêncio em relação a essas questões. A institucionalização dessa ordem, por meio da academia de gestão, tem ajudado a restringir, em escala global, o reconhecimento de outros tipos de estrategista, organização, instituição e capitalismo pela área.

Essa distinção disciplinar imposta pelos EUA continua sofrendo resistência pela área de EOs na Europa. Tais resistências informam a criação da perspectiva de estratégia como prática social como subárea de EOs. A aproximação desta perspectiva à área de GE nos EUA (e.g., criação de um grupo de interesse no Academy of Management em 2009 e também no Strategic Management Society) tem tanto ajudado a fortalecer a área de EOs europeia quanto a afastar a pesquisa em estratégia de grandes questões em termos globais na Europa (Vaara \& Durand, 2012). No Brasil, onde a distinção hierárquica entre GE e EOs é menos intensa do que nos EUA, autores vêm criticando as limitações do conhecimento dominante de GE para produção de conhecimento que seja relevante para o país (Bertero, Vasconcelos, \& Binder, 2003, Bignetti \& Paiva, 2002; Faria, 2011), ainda que de forma menos contundente do que na área de EOs (e.g., Alcadipani \& Bertero, 2012). Críticas no Brasil têm indo além das críticas produzidas na Europa (Hambrick, 2004; Whittington, 2012) por contemplarem estrategistas e organizações alternativas (e.g., Saraiva, Carrieri, Aguiar, \& Brito, 2011), que são ignoradas também pela literatura europeia. A seguir, analisar-se-á como a ascensão da teoria de variedades do capitalismo e a subsequente criação da perspectiva de estratégia como prática social ajudaram mais a reforçar do que a atenuar os problemas protagonizados por GE.

\section{A Perspectiva Europeia de Capitalismo(s) em Estratégia}

Informada pelas forças do capitalismo histórico ocidentalista, a tese de variedades de capitalismo é uma resposta europeia aos diversos processos e mecanismos de imposição do capitalismo neoliberal ocidental liderado pelos EUA como única opção (Hall \& Soskice, 2001). Essa resposta institucional promoveu a legitimidade de instituições e organizações europeias que não reproduziam exatamente os discursos enunciados pelos EUA. A literatura de RI afirma que bases de legitimidade nacionais e regionais devem ser defendidas, preservadas e difundidas ou impostas internacionalmente segundo interesses nacionais ou regionais de ordem econômica e (geo)política (Clark, 2009). Estrategistas de Estado, juntamente com grandes corporações e, eventualmente, com o apoio da sociedade civil, devem mobilizar diferentes tipos de poder político, em especial por meio da combinação de coerção, cooptação e sedução (Hurd, 1999; Nye, 2008). Bases de legitimidade nacionais ou regionais classificadas como ameaçadoras devem ser legitimamente modificadas por meio de mecanismos de institucionalização que, venham a reforçar os privilégios dos conquistadores em relação aos conquistados (Hurrell, 2005).

A literatura de RI afirma que o poder de estrategistas ou países no sistema internacional ou interestatal torna-se mais efetivo quando exercido não somente pelo uso da força, que deve ser mobilizada quando necessária, mas principalmente por meio de autoridade e legitimidade (Clark, 2009; Cronin, 2001). Enquanto a teoria institucional dominante no campo da gestão (e.g., Ingram \& Silverman, 2002; Kostova \& Roth, 2002) pressupõe que a construção de legitimidade por agentes e organizações individuais não tem ligação com mecanismos e sistemas interestatais de dominação, resultado de um longo processo disciplinar de "despoliticização da política", fomentado nas instituições acadêmicas pelo capitalismo histórico ocidentalista (Amin, 2014, p. xvii), a literatura de estudos internacionais entende legitimidade como um tipo especial de obediência ou dominação, que difere, por um lado, do comportamento instrumental ou autointeressado, e, por outro, "de regras coercitivas impostas diretamente ao outro" (Hurrell, 2005, p. 16). Legitimidade, portanto, não é simplesmente o que as pessoas tendem a aceitar sob uma perspectiva sociológica, vis-à-vis disfunções coletivas geradas pela racionalidade individual, como previsto por Max Weber, mas sim o que as pessoas aceitam "em função de algum entendimento normativo ou processo de persuasão" (Hurrell, 2005, p. 16). Maior ou menor nível de aceitação em perspectiva social ou individual é explicado pela mobilização de mecanismos de 
poder (geo)político advindos do sistema interestatal (Symons, 2011) e de diferentes tipos e níveis de poder político - em especial autointeresse, cooptação e coerção (Hurd, 1999).

Segundo a literatura de estudos internacionais, com a ascensão do novo imperialismo (Harvey, 2003) e com a crescente preocupação com as economias emergentes após a crise financeira global de 2007-2008 (Amin, 2014), a questão central para estrategistas dos EUA passou a ser não exatamente a manutenção da ordem unilateral ou a obsolescência da hegemonia estadunidense devido à ascensão do resto, mas sim a capacidade de recrutar seguidores (Buzan, 2008) por meio da construção de modalidades de poder "que explorem assimetrias de poder e gerem (alguma) vantagem coletiva" (Clark, 2009 , p. 36). Em outras palavras, por meio da institucionalização em escala global de regimes de dominação que pareçam hegemonia benigna, para que alternativas sejam contidas de forma efetiva.

De acordo com a teorização institucional mais conhecida em gestão, instituições são de central importância em processos de mudança porque estas restringem a racionalidade dos indivíduos e fornecem bases de legitimidade que são difíceis de mudar (DiMaggio \& Powell, 1983). Essa teorização, que foi motivo de polêmicas importantes no Brasil devido ao seu caráter apolítico (ver Carvalho, Vieira, \& Goulart, 2005), continua dominante em gestão, e é uma das bases teóricas da teoria de variedades de capitalismo (VC). Segundo a teoria de VC, a legitimidade das instituições resulta de um complexo conjunto de relações sociais que está longe do controle ou de influência de organizações individuais (Hall \& Soskice, 2001). A literatura de gestão baseada nessa teorização afirma que a não adequação de organizações à ordem institucional prevalente representa risco para sua sobrevivência e, em segunda instância, para a própria dinâmica das instituições (Morgan \& Kristensen, 2006). Os poderes (geo)políticos de estrategistas das grandes corporações para influenciar instituições de seus países e internacionalmente não são contemplados pela teoria de VC.

A teoria de VC mantêm silêncio quanto a como e por que organizações e instituições de determinadas regiões ou contextos interferem em instituições de outras regiões ou contextos, especialmente no que diz respeito às assimetrias estabelecidas pelo capitalismo histórico ocidentalista. Tampouco problematiza como a institucionalização da financeirização do capitalismo ocidentalista magnificou as assimetrias entre os $99 \%$ desprivilegiados e o $1 \%$ mais privilegiado da população no mundo euro-americano (Piketty, 2014). Ao representar a economia mundial como um agregado de economias independentes e ignorar as assimetrias do sistema interestatal vinculadas ao capitalismo histórico ocidentalista, a teoria de $\mathrm{VC}$ ajuda a impedir que pesquisadores de estratégia de economias emergentes abracem a teorização institucional produzida pelo campo de estudos internacionais. A imposição histórica de instituições euro-americanas em países menos desenvolvidos ou emergentes por meio de mecanismos de coerção e sedução tem sido mantida invisível pela teoria de VC.

Essa teoria foi criada na Europa (mais especificamente, no norte da Europa), e foi institucionalizada em escala global devido a uma estrutura de geopolítica do conhecimento vinculada ao capitalismo histórico que tende a reforçar os privilégios dos conquistadores. A teoria de VC tem produzido debates não apenas na Europa, mas também no Brasil (Boschi, 2011; Diniz, 2010). Entretanto, os debates produzidos no Brasil são ignorados pela literatura europeia e também pela de estratégia como prática social. Autores brasileiros vinculados à área de estudos internacionais apontam que a teoria de variedades adota "uma visão extremamente primeiro-mundista (americanista ou eurocêntrica)" (Boschi, 2011, p. 8), que acaba por reforçar o capitalismo ocidentalista.

$\mathrm{Na}$ Europa, pesquisadores passaram a se concentrar em comparações de processos de institucionalização de sistemas de negócios entre países e na compreensão das instituições da sociedade que criam acesso a recursos críticos, tais como capital e trabalho, que supostamente governam e moldam sistemas nacionais de negócios. As instituições, tidas como benignas e desconectadas do sistema interestatal histórico, formam os pilares das relações sócio-políticas e econômicas que ajudam a reproduzir e a difundir as principais bases nacionais ou regionais de legitimidade e autoridade (Whitley, 1999). Por sua vez, as instituições complementares - i.e., aquelas que modelam as regras seguidas por organizações e grandes corporações - são descritas como reprodutoras e reforçadoras das bases nacionais (Morgan, 2007). 
Compreender como grandes corporações respondem estrategicamente a essa representação de diversidade e complexidade institucional passou a ser um dos focos da literatura na Europa em meados dos anos 2000 (Morgan \& Kristensen, 2006). Com base na ideia de que grandes corporações são uma instituição universal, a maior parte das pesquisas vem se restringindo a análises comparadas dentro da Europa (Dörrenbächer \& Geppert, 2009), e não problematizando o papel central das corporações no fomento de reformas institucionais no resto do mundo. Mais recentemente, pesquisadores europeus passaram a analisar tais fenômenos na Ásia, sob a perspectiva ocidentalista inaugurada pelo capitalismo histórico (Gamble, 2010). O pressuposto de que instituições ocidentais são eminentemente superiores está implícito na "visão extremamente primeiro-mundista (americanista ou eurocêntrica)" imposta pela teoria europeia de VC, como aludido por Boschi (2011, p. 8). Autores focam as disputas entre organizações e instituições que transitam entre países ou regiões: ignorando a teorização produzida pela área de estudos internacionais, eles argumentam que grandes corporações europeias têm capacidade de se adaptar e operar em múltiplos contextos, não apenas incorporando regras locais, mas também, eventualmente, influenciando instituições locais (Dahan, Doh, \& Guay, 2006). Ao ignorar estruturas e mecanismos de dominação estabelecidos pelo capitalismo histórico, essa literatura sugere que as instituições do resto do mundo estão inevitavelmente subordinadas a processos de institucionalização comandados pelo mundo euro-americano. Esse quadro ajuda a compreender os argumentos que afirmam que a perspectiva europeia de estratégia como prática social tem sido refratária a críticas e tem ignorado questões políticas (ver Carter et al., 2008; Clegg et al., 2011; Vaara \& Whittington, 2012). A análise aqui proposta vai além dessas críticas por tornar visível para pesquisadores que se baseiam na teoria de variedades do capitalismo e na perspectiva de estratégia como prática social os mecanismos que explicam o domínio euro-americano em GE e em ciências sociais.

Brasil, China, Índia e Rússia são exemplos de países que operam sob regras e instituições que se caracterizam tanto pela conformidade quanto pela diversidade em relação à ordem euro-americana. Essa diversidade vem sendo classificada tanto como inferioridade ou como ameaça ao longo de mais de quinhentos anos pelas forças do capitalismo ocidentalista histórico (Amin, 2014). Por sua vez, na área de estudos internacionais, instituições locais são analisadas como cruciais para a ascensão dos países dos BRICs. As instituições que são classificadas como ameaçadoras ao Ocidente impediram que o poder de intervenção e de articulação do Estado não tivesse sido completamente desmobilizado pelas reformas estruturais neoliberais implementadas dos anos 1980 e 1990 nas economias emergentes (Arbix, Comin, Zilbovicius, \& Abramovay, 2002; Arrighi, 2007; Henisz, Zelner, \& Guillén, 2005).

Essa análise da teoria de VC, sob uma perspectiva de geopolítica do conhecimento e enunciada em uma economia emergente, torna visível, inclusive para acadêmicos do mundo euro-americano, não apenas o processo de deslegitimação de outros tipos de estrategista, organização e capitalismo, mas também as restrições epistêmicas e institucionais enfrentadas pela área para a construção e a legitimação de uma área não-ocidentalista. Tornar visível o que vem sendo invisibilizado há alguns séculos não é suficiente, pois pode até mesmo acirrar a divisão entre conquistadores e conquistados. Para tanto, a área de estratégia no Brasil deve engajar a literatura de estudos internacionais e reforçar a legitimidade de outros tipos de estrategistas, organizações e instituições que são importantes para a ascensão das economias emergentes e de diferentes modalidades de capitalismo ou alternativas, como ilustrada na seção a seguir, e propor a coconstrução internacional de uma área não ocidentalista de estratégia baseada em diálogos e intercâmbios institucionais com outras economias emergentes e com o mundo euroamericano.

\section{Repensando Estratégia no (e a Partir do) Brasil}

A criação da área acadêmica de estratégia no Brasil no campo da administração ocorreu durante as décadas de 1960 e 1970, em um período de crescimento econômico do país em que prevalecia a tese de que o capital estrangeiro e as elites empresariais locais associadas ao Estado eram centrais para o desenvolvimento de países subdesenvolvidos (Campos, 1963). O entendimento de que o crescimento das empresas nacionais e de subsidiárias de corporações multinacionais demandava melhores 
mecanismos de coordenação e controle, e a crise da hegemonia dos EUA no sistema do capitalismo histórico, devido à ascensão de movimentos anti-imperialistas em resposta à Guerra do Vietnã (Wallerstein, 2011), criaram um contexto parcialmente favorável à entrada e à difusão do conhecimento de GE vindo dos EUA. A disciplina de GE no Brasil foi virtualmente monopolizada pela literatura estadunidense em detrimento de outras teorizações e conhecimentos locais vinculados à área de estudos internacionais (Wanderley \& Faria, 2012). Esse processo, em paralelo à expansão de governos autoritários na América Latina no contexto da Guerra Fria, foi marcado pela ascensão do nacionalismo liderado por elites locais e por processos de neocolonialismo liderados pelos EUA, que eram descritos como processos de modernização por estrategistas de Estado, grandes corporações e instituições acadêmicas (Alcadipani \& Bertero, 2012; Alcadipani \& Caldas, 2012).

Com a forte presença do Estado no mercado, a escala e o escopo de atuação de corporações estrangeiras no país foram substancialmente ampliados. A ditadura militar e a ampliação do poder econômico-político dessas corporações viabilizaram a expansão do capitalismo ocidentalista comandado pelos EUA na América Latina, supostamente para modernizar a região e combater o avanço do comunismo (Alcadipani \& Bertero, 2012; T. Santos, 1994). O mercado brasileiro se caracterizou, então, por forte presença de organizações públicas e privadas, e por correspondentes estrategistas (Lima, 1999). A estagnação da economia mundial na década de 1980, em um contexto de instabilidade monetária e de recessão econômica causada pela dissolução do sistema de Bretton Woods pelos EUA e pela crescente financeirização do capitalismo ocidentalista neoliberal, juntou-se a um contexto de crise do neodesenvolvimentismo no Brasil e em outros países da América Latina submetidos a imensos volumes de dívida externa gerados pela manipulação do sistema monetário pelos EUA. Esse quadro imediatamente abalou a legitimidade de organizações e estrategistas ligados à esfera governamental no país. Comandados por estrategistas de Estado dos EUA, as instituições neoliberais do Consenso de Washington promoveram um amplo questionamento sobre o papel do Estado e também reformas político-econômicas e institucionais correspondentes (Diniz, 2000; Diniz \& Bochi, 2003), baseadas na fórmula D-L-P - i.e., Desregulamentação-Liberalização-Privatização - em diversas regiões e países (Steger \& Roy, 2010).

Durante a transição entre a ditadura militar e a redemocratização, a imposição da agenda neoliberal no Brasil foi acompanhada de processos importantes de resistência. Debates teóricos acerca do binômio desenvolvimento e modernização, e sobre o papel estratégico de instituições da região como alternativa ao chamado capitalismo dependente (ver Diniz, 2000; Martins, 2011) ajudaram a atenuar a institucionalização da área de GE no país e a construir condições para a realização de alternativas. Esse quadro epistêmico específico foi viabilizado por resistências marcantes de países da América Latina e outras economias emergentes aos processos neoliberais de imposição (Martins, 2011; Shefner \& Fernández-Kelly, 2011). Frente às pressões e aos incentivos para minimizar o Estado, grupos de políticos, instituições, movimentos sindicais, movimentos sociais - representando uma diversa gama de estrategistas, em franca oposição aos cânones da área de GE - lograram êxito na manutenção da presença estatal em diversos setores (Diniz, 2000) e na construção de processos de reconstituição do Estado, sociedade e mercado (Lima \& Coutinho, 2007), que não podiam ser previstos ou mapeados por teorizações eurocêntricas tanto de esquerda quanto de direita (ver Martins, 2011). Devido ao capitalismo histórico, esse importante quadro não podia ser contemplado pela teoria de $\mathrm{VC}$ nem pelos proponentes da perspectiva de estratégia como prática social.

As reformas institucionais mais intensas promovidas pelo capitalismo neoliberal acabaram por prevalecer. O modelo de economia política centrado no Estado foi majoritariamente classificado como intervencionista e antidemocrático. O Estado e as organizações públicas passaram a ser descritos legítima e abertamente como ineficientes, incompetentes e corruptas não apenas pela mídia em geral, mas, em especial, por produções acadêmicas produzidas por acadêmicos locais (Diniz, 2000; Diniz \& Boschi, 2003).

A privatização de empresas públicas, a realização de reformas de Estado e a desregulamentação dos mercados passaram a ser defendidas por diversos setores da sociedade e legitimadas pela literatura de gestão (Diniz, 2000; Henisz et al., 2005). Em consonância com uma política de maior inserção do país em regimes internacionais estabelecida pela administração de FHC, esse contexto marca o período 
mais intenso de deslegitimação de outros tipos de organização e de estrategista na literatura de GE, e também a entrada no país de grande volume de corporações estrangeiras, investimentos diretos estrangeiros (IDE), especialmente por meio de privatizações e conhecimentos/instituições de gestão (ver Alcadipani \& Caldas, 2012).

A Crise Asiática, no final dos anos 1990, marcou o ocaso do Consenso de Washington e promoveu o engajamento dos reformistas neoliberais com governos locais e estrategistas de governo por meio de mecanismos de dominação via coerção e cooptação que parecessem cooperação e participação, baseadas a partir de então em reformas institucionais incrementais (Hurrell, 2009; Stiglitz, 2002). Curiosamente, essa crise de legitimidade do capitalismo histórico e a crise subsequente, de confiança nas grandes corporações do início dos anos 2000, ajudaram a fortalecer estrategistas e organizações vinculadas ao Estado e a movimentos sociais no Brasil e em outros países do resto do mundo.

Contrarreformas a tais processos contra-hegemônicos foram iniciadas após os eventos de 11 de setembro de 2001, com o apoio de discursos focados na potencial ameaça das economias emergentes à ordem mundial. Novas bases de autoridade legítima para as grandes corporações foram mobilizadas pelo novo imperialismo, com base na institucionalização de um regime de dominação que parecesse hegemonia benigna (Hurrell, 2009). Como sugerido pela literatura de estudos internacionais, esse regime de dominação incluiu reformas no âmbito acadêmico do mundo euro-americano; a autonomia da universidade como esfera pública democrática foi substancialmente reduzida a partir do início dos anos 1990 (Readings, 1996) e posteriormente desmantelada por processos que incluíram uma complexa combinação de políticas de corporatização, mercantilização e militarização (Giroux, 2009, 2012; Philo \& Miller, 2001). No Brasil, esse quadro ajudou a ampliar o domínio da literatura produzida nos EUA na academia local e a sedimentar uma perspectiva apolítica na área de gestão.

As seguidas crises do capitalismo neoliberal e a política proativa de inserção internacional do país, a partir de uma abordagem desenvolvimentista e marcada pela colaboração com países com interesses similares durante a administração Lula (Lima \& Hirst, 2009), criaram condições para resistências acadêmicas em gestão baseadas em diálogos com a área de estudos internacionais (e.g., Carvalho et al., 2005; Guedes, 2010; Rodrigues et al., 2012). Autores e instituições locais que criticavam abertamente a globalização neoliberal e promoviam contramovimentos ao processo de deslegitimação de estrategistas de Estado (e.g., Arbix et al., 2002) puderam ser reconhecidos. A ascensão das economias emergentes e da esquerda na América Latina e a ascensão da literatura em gestão informada pela teoria pós-colonialista (e.g., Prasad, 2003) criaram condições para críticas quanto à subordinação de pesquisas em GE no Brasil ao conhecimento produzido nos EUA (e.g., Bignetti \& Paiva, 2002). Ainda que essa literatura enfrente dificuldades para ser aceita por publicações e instituições euro-americanas que comandam instituições e rankings no campo da gestão, cabe destacar que a perspectiva de estratégia como prática social no Brasil passou a se engajar com teorizações institucionais que desafiam a universalização proposta por pesquisadores europeus (e.g., Maciel \& Augusto, 2013; Saraiva et al., 2011).

As condições institucionais continuam mudando no contexto internacional, criando melhores condições para a construção de uma área não ocidentalista de estratégia por economias emergentes. Economias emergentes saíram da condição de devedores e assumiram a posição de doadores no sistema internacional. A China substituiu o Consenso de Washington pelo Consenso de Beijing, e passou a fomentar desenvolvimento e outro tipo de capitalismo na África e na América Latina. A cúpula de Fortaleza, realizada em julho de 2014, propôs o Consenso do Rio como mais uma alternativa oferecida pelos BRICS. Correspondentemente, a literatura de estudos internacionais confirma que a não subordinação ao ocidentalismo liderado pelos EUA informa a ascensão das economias emergentes e que esta é necessária para a superação da crise de transição do capitalismo histórico e para a construção de alternativas não ocidentalistas (Diniz, 2010; Harvey, 2010). Por sua vez, a área de GE continua tentando controlar a ascensão das economias emergentes por meio de mecanismos de dominação que pareçam com hegemonia benigna, especialmente após a crise neoliberal deflagrada em Wall Street em 2007-2008 e aprofundada por crises na Europa e em outras partes. Entretanto, o neocolonialismo subjacente tem sido classificado como inaceitável até mesmo pela literatura de EOs produzida na Europa e nos EUA (e.g., Murphy \& Zhu, 2012; Prasad, 2012). 
No Brasil e em outras economias emergentes, a presença do Estado e de organizações controladas ou vinculadas ao governo e à sociedade dos desprivilegiados continua forte. A difusão do temor ocidentalista de que economias emergentes e seus estrategistas criem e disseminem um tipo ameaçador de capitalismo - em especial o chamado capitalismo de Estado - ajuda a explicar o reconhecimento de diferenças e os processos correspondentes de gestão das diferenças pelo pós-Consenso de Washington (Gonçalves, 2005; Hurrell, 2009). Por meio de políticas de engajamento e resistência a tais mecanismos, economias emergentes mantiveram considerável poder de governança por meio de reestruturação de suas organizações e instituições de governo (Diniz, 2000; Eaton \& Dickovick, 2004; Swyngedouw, 2005) e de crescente importância nos diferentes âmbitos de governança global (Hurrell \& Sengupta, 2012) e também na promoção de alternativas responsáveis ao ocidentalismo extremado. Lançada em 2003, como um contramovimento ao avanço do novo imperialismo e à crise do capitalismo financeiro, a iniciativa IBAS, que reúne Índia, Brasil e África do Sul, ilustra, no âmbito das economias emergentes, não apenas "a renovada centralidade do desenvolvimentismo, mas também a ênfase renovada na cooperação Sul-Sul” (Lima \& Hirst, 2009, p. 50).

Estrategistas do Estado e de organizações públicas continuam sendo de central importância para promoção de desenvolvimento e construção de mercados no país e no exterior. O mercado de etanol no Brasil ilustra esse padrão. Iniciado na década de 1970, o programa ProÁlcool era uma política de incentivo ao setor sucroalcooleiro e para o desenvolvimento de um combustível alternativo ao petróleo, frente à Crise do Petróleo de 1973. Em seus primeiros estágios, entre 1975 e 1985, houve grande intervenção do Governo Federal no fomento desse mercado sob uma perspectiva nacionalista (RosilloCalle \& Cortez, 1998). Em 1986, o mercado se consolidou, com a produção de quase 700 mil automóveis movidos a etanol. Entre 1986 e 2000, esse padrão foi substituído por modos de governança com menor interferência governamental. Em 2000, após a crise do Consenso de Washington, o Estado retomou o etanol, a partir de então sob uma perspectiva desenvolvimentista transnacionalista em resposta ao avanço do novo imperialismo. Novas tecnologias e novas políticas governamentais promoveram a expansão do mercado de etanol no Brasil e a maior atuação do país, juntamente com outros países do resto do mundo, no âmbito de governança global de energia. Políticas focadas em segurança energética e meio ambiente, de acordo com o propósito de promover alternativas à crise do capitalismo financeiro e de conter a crescente importância geopolítica do setor de energia, após a ascensão do unilateralismo dos EUA, foram acompanhadas pelo fortalecimento de políticas e estratégias envolvendo associações de produtores de cana-de-açúcar, organizações públicas e privadas de fomento, ONGs, entre outras (Kohlhepp, 2010), por vasta gama de estrategistas.

Esse quadro demanda e justifica que o Brasil e outras economias emergentes desafiem a hierarquia entre conquistadores e conquistados que fundou o capitalismo histórico, e assumam responsabilidades pela coconstrução da área de estratégia. Devemos lembrar que autores importantes resistem há mais de duas décadas ao processo de deslegitimação de outros tipos de estrategistas (especialmente aqueles vinculados ao governo e também à sociedade de uma forma mais ampla) (e.g. Fachin \& Silva, 1984) e ressaltar que uma nova geração vem promovendo alternativas teóricas e disciplinares por meio do engajamento da perspectiva de estratégia como prática social com estrategistas que foram deslegitimados pela literatura euro-americana de estratégia. Além disso, a inauguração do tema Estratégia, Governo e Desenvolvimento pela área de Estratégia em Organizações do EnANPAD no final da década passada e o crescimento do mesmo ao longo desses anos também ilustram a existência de condições para a construção de uma área não ocidentalista de estratégia no país.

\section{Considerações Finais}

Por meio de um diálogo com a área de estudos internacionais, este artigo argumentou que a área euro-americana de GE se fundamenta em dois pressupostos que traduzem sua vinculação ao capitalismo ocidentalista liderado pelos EUA e correspondente oposição a outros tipos de capitalismo e alternativas não ocidentalistas: (a) outros tipos de estrategista e organização devem ser substituídos por estrategistas de grandes corporações ou subordinados a estes; e (b) o resto do mundo deve continuar copiando as 
instituições estabelecidas pela modernidade ocidentalista. Argumentamos que economias emergentes devem promover a coconstrução, por meio de diálogos e intercâmbios com outras economias emergentes e com o mundo euro-americano, de uma área não ocidentalista de estratégia.

Especialmente após os eventos de 11/9 e a ascensão do unilateralismo dos EUA, a literatura de GE passou a argumentar que tanto as grandes corporações e seus CEOs quanto a ordem global estão sob ameaça, devido especialmente a deficiências governamentais ou institucionais de economias emergentes. A perspectiva de estratégia como prática social, criada na Europa e baseada na teoria de variedades de capitalismo com o propósito de contrapor a ofensiva neoliberal liderada pelos EUA, tem limitado possibilidades na área por não reconhecer sua própria vinculação ao capitalismo histórico. Estrategistas de organizações governamentais do resto do mundo continuam sendo deslegitimados pela hegemonia euro-americana em GE, enquanto estrategistas de Estado do mundo euro-americano, que sustentam a controversa trajetória do capitalismo ocidentalista histórico, são mantidos invisíveis.

$\mathrm{O}$ artigo mostrou que o domínio contemporâneo da literatura euro-americana de GE tem se sustentando principalmente pela difusão de temores ocidentalistas de que economias emergentes representem uma ameaça para a ordem global. Restringidos pelas forças do capitalismo ocidentalista histórico, a maioria de pesquisadores e instituições da área enfrenta dificuldades para reconhecer que economias emergentes devem e podem assumir responsabilidades acadêmicas nesta área do conhecimento. Conhecimentos produzidos no Brasil sob a perspectiva de geopolítica do conhecimento proposta neste artigo devem ser úteis para que pesquisadores e instituições do mundo euro-americano também reconheçam alternativas que a matriz ocidentalista vem restringindo há mais de cinco séculos.

Para evitar uma politização inversa da perspectiva desenvolvida neste artigo para a construção de uma área não ocidentalista de estratégia - que corre o risco de ser classificada como mais uma prática antiocidente por instituições que comandam a área de GE, ou oportunisticamente apropriada por elites locais, é necessário construir uma área de estratégia no Brasil que reforce a legitimação de outros tipos de estrategista, organização e capitalismo em paralelo à coconstrução de uma área não ocidentalista de estratégia com base em diálogos críticos e intercâmbios envolvendo maior ou menor nível de assimetria com outras economias emergentes e com o mundo euro-americano.

\section{Agradecimentos}

Os autores agradecem o competente trabalho dos revisores anônimos e também as atividades de acompanhamento e revisão efetuadas pelo Editor e pela equipe editorial da RAC. O primeiro autor também agradece ao CNPq pelo apoio ao projeto de pesquisa vinculado a este artigo. Cabe aos autores a responsabilidade final pelo conteúdo deste artigo.

\section{Notas}

\footnotetext{
${ }^{1}$ Capitalismo histórico é um sistema social iniciado no final do século XV, na Europa, usado com o propósito de autoexpansão, em que capitalistas investem capital com o propósito de acumular mais capital, em substituição a processos que anteriormente eram conduzidos por meio do mercado. O sistema teve extraordinário impacto, desde então, por ter conseguido criar condições, especialmente por meio do sistema inter-estatal, para que outros fossem forçados a se conformar aos padrões ou a sofrer as consequências: como sistema em busca de monopolização, o capitalismo histórico "se expandiu em termos espaciais para cobrir o globo até final do século XIX ... e ainda cobre o globo inteiro” (Wallerstein, 2011, p. 19).

${ }^{2}$ De acordo com Harvey (2003), a expansão da acumulação capitalista neoliberal não se produz contemporaneamente prescindindo de elementos de coerção, seja na forma de sanções econômicas ou de intervenções militares. O novo imperialismo é fruto de uma fusão da ascensão e difusão do capitalismo neoliberal (Harvey, 2007) e das tendências a utilizar a coerção e intervenção militar aos territórios e formações sociais que se oporem a consentirem com a incorporarem ou interagirem com essa forma de organização da economia no âmbito global (Harvey, 2003).
}

${ }^{3}$ Segundo Grosfoguel, R. (2008). Para descolonizar os estudos de economia política e os estudos pós-coloniais. Revista Crítica de Ciências Sociais, (80), 115-147, com base em uma perspectiva descolonial, o período de mais de 450 anos de colonização 
de várias regiões do mundo por países Europeus ainda é um traço relevante contemporaneamente, não apenas nas relações internacional entre Estados, como também na própria construção de subjetividades e do imaginário social, a despeito da desvinculação jurídico-política em termos de administração colonial. Nesse sentido, o autor considera ser um "mito eurocêntrico" (p. 128) a ideia de que vivemos em uma era pós-colonial, uma vez que há continuidades entre o passado colonial e assimetrias de poder que ainda não foram rompidos, o que ajuda a perpetuar uma matriz eurocêntrica de poder. O autor defende ser necessário tratar tal mito "de modo a concretizar esse inacabado e incompleto sonho do século XX que é a descolonização" (Grosfoguel, 2008, p. 128).

${ }^{4}$ A principal preocupação da literatura europeia de estratégia como prática tem sido o lado humano da gestão estratégica das grandes corporações, sob uma perspectiva universalista eurocêntrica que mantêm invisível a geopolítica que informa a hegemonia ocidentalista em GE e nas ciências sociais.

${ }^{5}$ Estudos internacionais é um vasto campo que lida não apenas com análise de relações internacionais, mas também com questões políticas, econômicas, sociais, ambientais, geográficas, epistêmicas etc. que se estendem através de fronteiras nacionais. O campo de estudos internacionais é inerentemente interdisciplinar, contemplando um amplo leque de disciplinas acadêmicas, tais como antropologia, direito, história, geografia, economia, ciência política, sociologia, desenvolvimento, direitos humanos, religião, conhecimento, ciência e tecnologia, etc. Apesar de sua amplidão, a própria literatura de estudos internacionais ressalta que este campo tem sido liderado pelas grandes potências (em especial pelo Ocidente) (ver Guedes, A., \& Faria, A. (2010). Bringing the international into international management: new challenges. In A. Guedes \& A. Faria (Eds.), International management and international relations (pp. 231-242). London, NY: Routledge).

${ }^{6}$ Para fins de definição conceitual, hegemonia é trabalhada neste trabalho como um conceito que explica a existência de um equilíbrio delicado entre coerção e consenso na relação entre Estados nacionais, variando entre o exercício do poder direto e indireto, de modo a assegurara maior poder e apoio político de terceiros por parte dos mais fortes na relação, mas com a provisão de algum grau de autonomia de ação e respeito para os Estados e organizações mais fracos (Hurrell, 2005, 2009).

${ }^{7}$ O Consenso de Washington é um conjunto de políticas, desenvolvidas principalmente a partir de 1989, baseadas no pressuposto de que a adoção de práticas voltadas ao mercado, por parte dos governos - tais como a liberalização do comércio, privatizações, desregulamentação e reforma fiscal, é a melhor forma de promover desenvolvimento (Chang, H.-J. (2002). Rompendo o modelo. In G. Arbix, A. Comin, M. Zilbovicius, \& R. Abramovay (Orgs.), Brasil, México, África do Sul, Índia e China: diálogo entre os que chegaram depois (pp. 99-134). São Paulo: UNESP; USP; Henisz et al., 2005). Segundo diferentes autores e instituições, essa orientação não foi capaz de cumprir suas principais promessas.

${ }^{8}$ Segundo Baron (2010), ativistas estão envoltos em atividades que impedem, promovem ou direcionam mudanças sociais, políticas, econômicas ou ambientais. Com base no pressuposto de que ativismo gira necessariamente em torno das empresas e dos negócios, o autor afirma que o foco principal de análise em estratégia deve ser a compreensão de como ativistas interferem nas dinâmicas de empresas,

\section{Referências}

Accenture. (2008). Multi-polar world 2: the rise of the emerging-market multinational. Retrieved from http://www.accenture.com/SiteCollectionDocuments/PDF/MPW2.pdf

Alcadipani, R., \& Bertero, C. (2012). Guerra fria e ensino do management no Brasil: o caso da FGV/EAESP. Revista de Administração de Empresas, 52(3), 284-299. doi: 10.1590/S003475902012000300002

Alcadipani, R., \& Caldas, M. (2012). Americanizing Brazilian management. Critical Perspectives on International Business, 8(1), 37-55. doi: 10.1108/17422041211197558

Amin, S. (2014). Capitalism in the age of globalization. London: Zed Books.

Arbix, G., Comin, A., Zilbovicius, M., \& Abramovay, R. (2002). Brasil, México, África do Sul, Índia e China: diálogo entre os que chegaram depois. São Paulo: UNESP; USP.

Arrighi, G. (2007). Adam Smith in Beijing: lineages of the $21^{\text {st }}$ century. London: Verso.

Arrighi, G. (2012). O longo século XX. Rio de Janeiro: Contraponto.

Baron, D. (2010). Business and its environment (6th ed.). New Jersey: Prentice Hall.

Bertero, C., Vasconcelos, F., \& Binder, M. (2003). Estratégia empresarial: a produção científica brasileira entre 1991 e 2002. Revista de Administração de Empresas, 43(4), 48-62.

RAC, Rio de Janeiro, v. 18, Ed. Esp., art. 1, pp. 1-21, Dezembro 2014

WWw.anpad.org.br/rac (oc) EY-No 
Bignetti, L. P., \& Paiva, E. L. (2002). Ora (direis) ouvir estrelas!: estudo das citações de autores de estratégia na produção acadêmica brasileira. Revista de Administração Contemporânea, 6(1), 105-125. doi: 10.1590/S1415-65552002000100007

Boschi, R. (Org.). (2011). Variedades de capitalismo, política e desenvolvimento na América Latina. Belo Horizonte: Editora da UFMG.

Bowman, E., Singh, H., \& Thomas, H. (2002). The domain of strategic management: history and evolution. In A. Pettigrew, H. Thomas, \& R. Whittington (Eds.), Handbook of strategy and management (pp. 31-51). London: Sage.

Boyle, M.-E. (2004). Walking our talk: business schools, legitimacy, and citizenship. Business \& Society, 43(1), 37-68. doi: 10.1177/0007650303262638

Bremmer, I. (2010). The end of the free market: who wins the war between states and corporations. European View, 9(2), 249-252. doi 10.1007/s12290-010-0129-z

Brenner, N. (1999). Beyond state-centrism? Space, territoriality, and geographical scale in globalization studies. Theory and society, 28(1), 39-78. doi: 10.1023/A:1006996806674

Brugmann, J., \& Prahalad, C. (2007). Cocreating business: new social compact. Harvard Business Review, 85(2), 80-90.

Buzan, B. (2008). A leader without followers? The United States in world politics after Bush. International Politics, 45(5), 554-570. doi 10.1057/ip.2008.21

Campos, R. (1963). Economia, planejamento e nacionalismo. Rio de Janeiro: Apec.

Carter, C., Clegg, S., \& Kornberger, M. (2008). Strategy as practice? Strategic Organization, 6(1), 8399. doi $10.1177 / 1476127007087154$

Carvalho, C., Vieira, M., \& Goulart, S. (2005). A trajetória conservadora da teoria institucional. Revista de Administração Pública, 39(4), 849-874.

Chandler, A. D. (1977). The visible hand. Cambridge, MA: Harvard University Press.

Chase-Dunn, C. (2010). Globalization from below: toward a democratic global commonwealth. Journal of Globalization Studies, 1(1), 46-57. doi 10.1177/0002716202058001006

Clark, I. (2009). Bringing hegemony back in: the United States and international order. International Affairs, 85(1), 23-36. doi: 10.1111/j.1468-2346.2009.00778.x

Clegg, S., Carter, C., Kornberger, M., \& Schweitzer, J. (2011). Strategy: theory and practice. London: Sage.

Clegg, S., Ibarra-Colado, E., \& Bueno-Rodriguez, L. (Eds.). (1999). Global management: universal theories and local realities. London: Sage.

Cronin, B. (2001). The paradox of hegemony: America's ambiguous relationship with the United Nations. European Journal of International Relations, 7(1), 103-130. doi: $10.1177 / 1354066101007001004$

Dahan, N., Doh, J., \& Guay, T. (2006). The role of multinational corporations in transnational institution building: a policy network perspective. Human Relations, 59(11), 1571-1600. doi: $10.1177 / 0018726706072854$

Davis, I. (2006). "Soft” leadership in business. McKinsey Quarterly, 2, 4-5. 
DiMaggio, P., \& Powell, W. (1983). The iron cage revisited: institutional isomorphism and collective rationality in organizational fields. American Sociological Review, 48(2), 147-160.

Diniz, E. (2000). Globalização, reformas econômicas e elites empresariais. Rio de Janeiro: Editora FGV.

Diniz, E. (2010). Estado, variedades de capitalismo e desenvolvimento em países emergentes. Desenvolvimento em Debate, 1(1), 7-27.

Diniz, E., \& Boschi, R. R. (2003). Empresariado e estratégias de desenvolvimento. Revista Brasileira de Ciências Sociais, 18(52), 15-33. doi: 10.1590/S0102-69092003000200002

Dörrenbächer, C., \& Geppert, M. (2009). A micro-political perspective on subsidiary initiative-taking: evidence from German-owned subsidiaries in France. European Management Journal, 27(2), 100-112. doi: 10.1016/j.emj.2008.06.004

Eaton, K., \& Dickovick, J. (2004). The politics of re-centralization in Argentina and Brazil. Latin America Research Review, 39(1), 90-121. doi: 10.1353/lar.2004.0007

Fachin, R. C., \& Silva, L. C. M. da (1984). O comportamento político do dirigente de empresa estatal na formulação de estratégias. Revista de Administração de Empresas, 24(4), 243-252. doi: 10.1590/S0034-75901984000400035

Faria, A. (2011). Repensando redes estratégicas. Revista de Administração Contemporânea, 15(1), 84102. Recuperado de http://www.scielo.br/pdf/rac/v15n1/v15n1a06.pdf. doi: 10.1590/S141565552011000100006

Gamble, J. (2010). Transferring organizational practices and the dynamics of hybridization: Japanese retail multinationals in China. Journal of Management Studies, 47(4), 705-732. doi: 10.1111/j.1467-6486.2009.00876.x

Ghoshal, S. (2005). Bad management theories are destroying good management practices. Academy of Management Learning and Education, 4(1), 75-91. doi: 10.5465/AMLE.2005.16132558

Giroux, H. (2009). Democracy's nemesis: the rise of the corporate university. Cultural Studies - Critical Methodology, 9(5), 669-695. doi: 10.1177/1532708609341169

Giroux, H. (2012). The post 9/11 militarization of higher education. International Journal of Sociology of Education, 1(1), 27-53. doi: 10.4471/rise.2012.02

Gonçalves, R. (2005). Economia política internacional: fundamentos teóricos e as relações internacionais do Brasil. Rio de Janeiro: Elsevier.

Guedes, A. (2010). Negócios internacionais e gestão internacional: evolução do campo teórico. In M. Oliveira (Org.), Multinacionais brasileiras (pp. 21-38). São Paulo: Bookman.

Hall, P., \& Soskice, D. (Eds.). (2001). Varieties of capitalism. Oxford: Oxford University Press.

Hambrick, D. C. (2004). The disintegration of strategic management: it's time to consolidate our gains. Strategic Organization, 2(1), 91-98. doi: 10.1177/1476127004040915

Harvey, D. (2003). New imperialism. Oxford: Oxford University Press.

Harvey, D. (2007). A brief history of neoliberalism. Oxford: Oxford University Press.

Harvey, D. (2010). The enigma of capital. London: Profile Books.

Harvey, D. (2014). Seventeen contradictions and the end of capitalism. Oxford: Oxford University Press. 
Henisz, W. J., Zelner, B. A., \& Guillén, M. F. (2005). The worldwide diffusion of market-oriented infrastructure reform, 1977-1999. American Sociological Review, 70(6), 871-897. doi: $10.1177 / 000312240507000601$

Hurd, I. (1999). Legitimacy and authority in international politics. International Organization, 53(2), 379-408. doi: 10.1162/002081899550913

Hurrell, A. (2005). Legitimacy and the use of the force: can the circle be squared? Review of International Studies, 31, 15-32. doi: 10.1017/S0260210505006765

Hurrell, A. (2009). Hegemonia, liberalismo e ordem global: qual é o espaço para potências emergentes? In A. Hurrell (Org.), Os BRICs e a ordem global (pp. 9-41). Rio de Janeiro: FGV.

Hurrell, A., \& Sengupta, S. (2012). Emerging powers, North-South relations and global climate politics. International Affairs, 88(3), 463-484. doi: 10.1111/j.1468-2346.2012.01084.x

Ibarra-Colado, E. (2006). Organization studies and epistemic coloniality in Latin America: thinking otherness from the margins. Organization, 13(4), 463-488. doi: 10.1177/1350508406065851

Ingram, P., \& Silverman, B. (2002). The new institutionalism in strategic management. Advances in Strategic Management, 19, 1-30.

Jacobs, L. R., \& King, D. S. (2010). Varieties of Obamaism: structure, agency and the Obama presidency. Perspectives on Politics, 8(3), 793-802. doi: 10.1017/S1537592710002033

Khanna, T., \& Palepu, K. (2006). Emerging giants: Building world class companies in developing countries. Harvard Business Review, 84(10), 60-69.

Khanna, T., Palepu, K., \& Sinha, J. (2005). Strategies that fit emerging markets. Harvard Business Review, 83(2), 63-76.

Kohlhepp, G. (2010). Análise da situação da produção de etanol e biodiesel no Brasil. Estudos Avançados, 24(68), 223-253. doi: 10.1590/S0103-40142010000100017

Kostova, T., \& Roth, K. (2002). Adoption of an organizational practice by subsidiaries of multinational corporations: institutional and relational effects. Academy of Management Journal, 45(1), 215233. doi: $10.2307 / 3069293$

Lima, E. (1999). Privatização e desempenho econômico: teoria e evidência. In F. Pereira (Org.), Financiamento do desenvolvimento brasileiro (Vol. 2, pp. 209-249). Brasília: IPEA.

Lima, M., \& Coutinho, M. (2007). Uma versão estrutural do regionalismo. In E. Diniz (Ed.), Globalização, estado e desenvolvimento: dilemas do Brasil no novo milênio (pp. 125-151). Rio de Janeiro: FGV Editora.

Lima, M., \& Hirst, M. (2009). Brasil como país intermediário e poder regional. In A. Hurrell (Ed.), Os Brics e a ordem global (pp. 43-73). Rio de Janeiro: FGV Editora.

Lipartito, K., \& Sicilia, D. (Eds.). (2004). Constructing corporate America. Oxford: Oxford University Press.

Maciel, C., \& Augusto, P. (2013). A practice turn e o movimento social da estratégia como prática: está completa essa virada?. Revista de Administração Mackenzie, 14(2), 155-178. doi: 10.1590/S1678-69712013000200007

Madeley, J. (2008). Big business, poor peoples (2nd ed.). London: Zed.

Mahajan, V., \& Banga, K. (2006). The 86\% solution. Upper Saddle River: Wharton School. 
Martins, C. (2011). Globalização, dependência e neoliberalismo na América Latina. São Paulo: Boitempo.

Matten, D. (2009). Review essay: "it's the politics, stupid!": reflections on the role of business in contemporary nonfiction. Business Society, 48, 565-576. doi: 10.1177/0007650309337123

Meltzer, A. (2012). Why capitalism? Oxford: Oxford University.

Mignolo, W. (2011). The darker side of western modernity. London: Duke University Press.

Morgan, G. (2007). National business systems research: progress and prospects. Scandinavian Journal of Management, 23(2), 127-145. doi: 10.1016/j.scaman.2007.02.008

Morgan, G., \& Kristensen, P. H. (2006). The contested space of multinationals: varieties of institutionalism, varieties of capitalism. Human Relations, 59(11), 1467-1490. doi: $10.1177 / 0018726706072866$

Murphy, J., \& Zhu, J. (2012). Neo-colonialism in the academy? Anglo-American domination in management journals. Organization, 19(6), 915-927. doi: 10.1177/1350508412453097

Nye, J. (2008). The powers to lead. Oxford: Oxford University.

Parmar, I. (2012). Foundations of the American century. New York: Columbia University Press.

Peng, M., \& Parente, R. (2012). Institution-based weaknesses behind emerging multinationals. Revista de Administração de Empresas, 52(3), 360-364. doi: 10.1590/S0034-75902012000300007

Pettigrew, A., Thomas, H., \& Whittington, R. (Eds.). (2002). Handbook of strategy and management. London: Sage.

Philo, G., \& Miller, D. (2001). Market killing. Harlow: Longman.

Pieterse, J. N., \& Peters, M. A. (2012). Understanding the sources of anti-westernism: a dialogue between Jan Nederveen Pieterse and Michael A. Peters. Policy Futures in Education, 10(1), 5969. doi: 10.2304/pfie.2012.10.1.59

Piketty, T. (2014). Capital in the twentieth first century. Belknap Press.

Porter, M. E., \& Kramer, M. R. (2006). Strategy and society: the link between competitive advantage and corporate social responsibility. Harvard Business Review, 84(12), 78-92.

Porter, M. E., \& Kramer, M. R. (2011). Creating shared value. Harvard Business Review, 89(1/2), 6277.

Prasad, A. (Ed.). (2003). Postcolonial theory and organizational analysis. New York: Palgrave.

Prasad, A. (Ed.). (2012). Against the grain. Denmark: Copenhagen Business School Press.

Quijano, A., \& Wallerstein, I. (1992). Americanity as a concept or the americas in the imaginary of the modern world-system. International Journal of Social Science, (134), 549-559.

Readings, B. (1996). University in ruins. Cambridge: Harvard University Press.

Rodrigues, S. B., Duarte, R. G., \& Carrieri, A. P. de (2012). Indigenous or imported knowledge in Brazilian management studies: a quest for legitimacy? Management and Organization Review, 8(1), 211-232. doi: 10.1111/j.1740-8784.2011.00276.x

Roper, J. (2005). Symmetrical communication: excellent public relations or a strategy for hegemony? Journal of Public Relations Research, 17(1), 69-86. doi: 10.1207/s1532754xjprr1701_6 
Rosillo-Calle, F., \& Cortez, L. A. B. (1998). Toward ProAlcool II: a review of the Brazilian bioethanol programme. Biomass and Bioenergy, 14(2), 115-124. doi: 10.1016/S0961-9534(97)10020-4

Rumelt, R. (2008, December). Strategy in a 'structural break'. McKinsey Quarterly, 1-9.

Santos, B. (2006). Globalizations. Theory, Culture \& Society, 23(2/3), 393-399. doi $10.1177 / 026327640602300268$

Santos, B. S. de (2009). A non-occidentalist west? Learned ignorance and ecology of knowledge. Theory, Culture \& Society, 26(7/8), 103-125. doi: 10.1177/0263276409348079

Santos, T. (1994). Evolução histórica do Brasil. Petrópolis: Vozes.

Saraiva, E. V., Carrieri, A. P. de, Aguiar, A. R. C., \& Brito, V. G. P. da (2011). Um "pas de deux" da estratégia com a arte: as práticas do grupo Corpo de Balé. Revista de Administração Contemporânea, 15(6), 1016-1039. Recuperado de http://www.scielo.br/pdf/rac/v15n6/04.pdf. doi: $10.1590 / \mathrm{S} 1415-65552011000600004$

Shefner, J., \& Fernández-Kelly, P. (Eds.). (2011). Globalization and beyond. University Park: Pennsylvania State University.

Sklair, L. (2011). The transition from capitalist globalization to socialist globalization. Journal of Democratic Socialism, 1(1), 1-14.

Steger, M. (2009). Globalisms. New York: Rowman \& Littlefield.

Steger, M., \& Roy, R. (2010). Neoliberalism: a very short introduction. Oxford: Oxford University Press.

Stiglitz, J. (2002). Globalization and its discontents. New York: W. Norton.

Suchman, M. C. (1995). Managing legitimacy: strategic and institutional approaches. Academy of Management Review, 20(3), 571-610. doi: 10.5465/AMR.1995.9508080331

Swyngedouw, E. (2005). Governance innovation and the citizen: the Janus face of governance-beyondthe-state. Urban Studies, 42(11), 20-31. doi: 10.1080/00420980500279869

Symons, J. (2011). The legitimation of international organizations: examining the identity of communities that grant legitimacy. Review of International Studies, 37(5), 2557-2583. doi: $10.1017 / \mathrm{S} 026021051000166 \mathrm{X}$

Vaara, E., \& Durand, R. (2012). How to connect strategy research with broader issues that matter? Strategic Organization, 10(3), 248-255. doi: 10.1177/1476127012452827

Vaara, E., \& Whittington, R. (2012). Strategy-as-practice: taking social practices seriously. Academy of Management Annals, 6(1): 285-336. doi: 10.1080/19416520.2012.672039

Wallerstein, I. (2011). Historical capitalism. London: Verso.

Wanderley, S., \& Faria, A. (2012). The Chandler-Furtado case: a de-colonial re-framing of a North/South (dis)encounter. Management \& Organizational History, 7(3), 219-236. doi: $10.1177 / 1744935912444355$

Whitley, R. (1999). Divergent capitalisms. Oxford: Oxford University Press.

Whittington, R. (1993). What is strategy: and does it matter? London: Routledge.

Whittington, R. (2012). Big strategy/small strategy. Strategic Organization, 10(3), 263-268. doi: $10.1177 / 1476127012452828$ 
Whittington, R., Jarzabkowski, P., Mayer, M., Mounoud, E., Nahapiet, J., \& Rouleau, L. (2003). Taking strategy seriously. Journal of Management Inquiry, 12(4), 396-409. doi: $10.1177 / 1056492603258968$

Whittington, R., \& Mayer, M. (2005). The European corporation: strategy, structure and social science. Oxford: Oxford University.

Wilson, D., \& Purushothaman, R. (2003). Dreaming with BRICs: the path to 2050 [Global Economic Papers n ${ }^{\circ}$ 99]. Goldman Sachs, New York, NY, USA.

Witcher, B. J., \& Chau, V. S. (2012). Varieties of capitalism and strategic management: managing performance in multinationals after the global financial crisis. British Journal of Management, 23(Suppl. SI), S58-S73. doi: 10.1111/j.1467-8551.2012.00816.x

Young, R. (2003). Postcolonialism: a very short introduction. Oxford: Oxford University Press. 